\title{
A trajetória profissional de cinco médicos do Programa Saúde da Família: os desafios de construção de uma nova prática
}

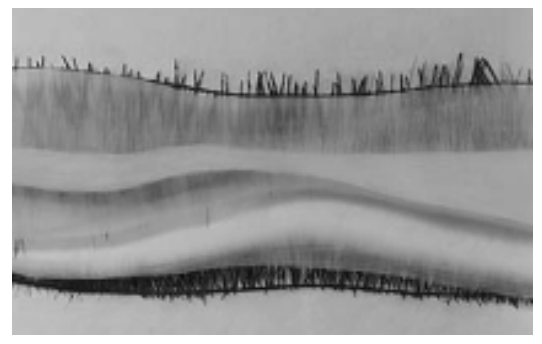

\author{
Ana Angélica Ribeiro de Meneses e Rocha ${ }^{1}$
}

Leny A. Bomfim Trad ${ }^{2}$

MENESES E ROCHA, A. A. R.; TRAD, L. A. B. The professional trajectory of five physicians working in the family health program: the challenges of building a new practice. Interface - Comunic., Saúde, Educ., v.9, n.17, p.303-16, mar/ago 2005.

This study analyzes the professional trajectories of five doctors working within the Family Health Program (PSF) in a municipal district of the Northeast of Brazil. Through life histories, circumscribed to the examination of the professional sphere, the study focuses on the following marks in the construction of their careers: the choice of the profession, the process of professional formation, and insertion in the job market, particularly, within the PSF. The data indicates that PSF has become a new job market for doctors. The analysis of their practice in this context reveals, however, a tension between clinical knowledge, that operates within biomedical rationality and is socially legitimated, and the preventive-promotional actions that gain priority the PSF. At the same time, PSF seems to be a potential locus for operating transformations in the medical professional that, as a subject, is capable of transforming the significance of his/her practice, redeeming its human and social dimensions.

KEY WORDS: physician; trajectory; health family; health practice.

Este estudo analisa as trajetórias profissionais de cinco médicos inseridos no Programa de Saúde da Família (PSF) em um município do Nordeste do Brasil. Por meio de histórias de vida circunscritas ao âmbito profissional, o estudo focaliza os seguintes marcos na construção de suas trajetórias: a escolha da profissão, o processo de formação profissional, a inserção no mercado de trabalho, particularmente, no âmbito do PSF. Os dados mostram que o PSF configura-se como um novo mercado de trabalho para o médico. A análise de sua prática neste contexto revela, entretanto, uma tensão entre um saber clínico, que opera na racionalidade biomédica e é socialmente legitimado, $e$ as ações de caráter preventivo-promocional, priorizadas pelo programa. Ao mesmo tempo, o PSF parece ser um locus potencial para operar transformações no profissional médico que, enquanto sujeito, é capaz de ressignificar sua prática, resgatando dimensões humanas e sociais.

PALAVRAS-CHAVE: médico; trajetória; saúde da família; prática de saúde.

\footnotetext{
${ }^{1}$ Professora, Instituto de Saúde Coletiva, Universidade Federal da Bahia (ISC/UFBA), Salvador, Ba. < anaerocha@uol.com.br>

${ }^{2}$ Professora, ISC/UFBA. <trad@ufba.br>
}

${ }^{1}$ Av. Sete de setembro, 3189

Ed. Ibirapuera, ap. 201

Salvador, BA

40.130-000 


\section{Introdução}

O Programa de Saúde da Família é apresentado no contexto políticoinstitucional brasileiro como uma proposta alternativa ao modelo de atenção fragmentado, calcado na compra e venda de serviços, num enfoque biologicista $e$ centrado no indivíduo. Espera-se, sobretudo, reordenar a atenção básica de saúde, com a implantação de uma equipe multiprofissional atuando em um território definido, em uma população adstrita, com oferta programada, tendo a família como núcleo de atenção. O PSF apresenta princípios e diretrizes que se revelam contra-hegemônicos na lógica de organização de serviços e nas práticas de saúde, destacando ainda a necessidade de ações com enfoque sobre problemas, requerendo planejamento e programação local, com a participação comunitária e com ênfase na intersetorialidade.

Um dos desafios para implementação dos princípios do PSF consiste em envolver os profissionais inseridos no programa em um amplo processo de reorientação do trabalho em saúde. Nesta questão deve-se levar em conta especificidades disciplinares - particularmente no que se refere à racionalidade dominante em cada campo - às experiências de formação $e$ à inserção profissional destes sujeitos, sem esquecer a interferência do mercado neste processo.

Analisando, especificamente, o caso do médico, a discussão sobre sua inserção no PSF deve levar em conta peculiaridades da trajetória social da própria Medicina. Entre os aspectos a serem considerados, vimos com Donangelo (1979), que a medicina tende a se revestir, mais facilmente, de um caráter de neutralidade face às determinações sociais. Característica essa que pode contribuir para uma prática que tende a se distanciar das necessidades de saúde da população.

O conhecimento médico, de acordo com Schraiber (1993, p.23), é dependente de um contexto específico de produção da ciência em cada tempo e lugar e pode, em certo sentido, ser considerado "limitado em medida $e$ atributo". Este conhecimento é traduzido em práticas relativamente autônomas e elitizadas que se organizam sob a forma de monopólio, acirrando seu teor corporativo. Deve-se reconhecer, sobretudo, a centralidade histórica da medicina, e por extensão, do profissional médico na organização dos serviços $e$ práticas de saúde.

Do ponto de vista da racionalidade que orienta a prática médica, concorda-se com Schraiber (1993), que esta é um misto de arte e técnica, submetida a uma ética técnico-moral dependente. Trata-se de uma prática que se expressa inevitavelmente enquanto intervenção sobre a vida de outro(s). A medicina se expressa enquanto um cuidado necessariamente diverso e qualitativo e que tem como objeto o ser humano (Mendes Gonçalves, 1979). Este processo apresenta, portanto, uma dimensão técnica - que se expressa na ação instrumental - e uma dimensão social - que se estabelece em relações humanas, especialmente delicadas.

Observa-se que o médico mantém com outros profissionais e pacientes, relações que tendem a se configurar nos termos propostos por Habermas (1990). São relações marcadas pela imediatez e refletem um poder consolidado graças a um saber técnico que é transmitido e cristalizado em redes de interação pelos quais os médicos transitam.

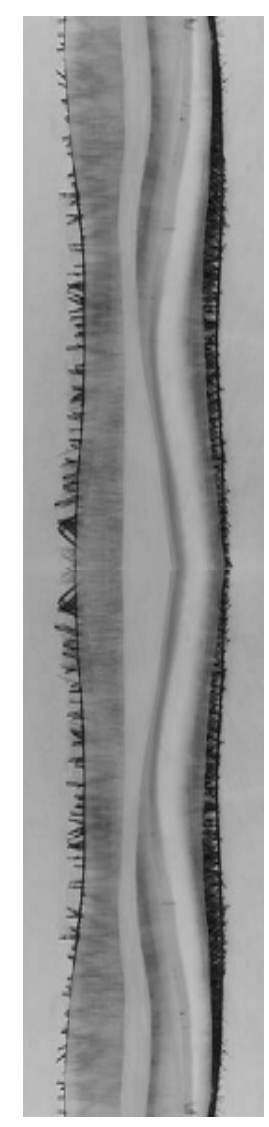


Deve-se considerar também os espaços nos quais a prática médica se desenvolve. São espaços que se traduzem em contextos organizacionais diversos, de âmbito público e privado, norteados por lógicas particulares de funcionamento. A maioria dos profissionais médicos concilia (ou tenta conciliar) múltiplos vínculos institucionais, o que lhes demanda um permanente movimento de ajuste situacional.

Este é um trabalho sobre trajetórias, entendendo este termo como uma linha, um percurso de sujeitos e objetos em movimento e das posições ocupadas por esses sujeitos e objetos. Da história da prática médica e do conhecimento que a fundamenta, aos espaços de atuação desse profissional $e$ das dinâmicas das relações que estabelece no contexto da sua prática. $\mathrm{O}$ presente estudo resgata as trajetórias profissionais de cinco médicos que hoje atuam no Programa de Saúde da Família em um município do Nordeste. São focalizados os seguintes marcos na construção das trajetórias desses sujeitos: a escolha da profissão, o processo de formação profissional, a inserção no mercado de trabalho, particularmente, no âmbito do PSF. O estudo enfatiza a experiência de incorporação do médico ao processo de trabalho do PSF.

\section{Metodologia}

Trata-se de uma investigação em saúde que privilegia a dimensão subjetiva. Assim sendo, concorda-se com Granda et al. (1999) que ao abordar a problemática da saúde a partir da perspectiva dos sujeitos, deve-se considerar as concepções destes sobre saúde-doença e os processos intersubjetivos de formulação e validação de sua prática.

O estudo foi realizado com cinco médicos que integram equipes do PSF de um município do estado de Alagoas. Foram determinantes na escolha do município, do qual selecionamos os médicos estudados, o tempo de implantação do PSF e o índice de cobertura, bem como a disponibilidade dos profissionais em participar do estudo. No ano de realização da pesquisa 2002 - o município selecionado tinha 66.000 habitantes e apresentava $80 \%$ de cobertura do PSF. O programa foi implantado no município em 1996 e em 2002 contava com 17 equipes. Do ponto de vista da organização do sistema local de saúde, destaca-se a precariedade de infra-estrutura das unidades básicas que se contrapõe a uma rede de serviços especializados $e$ hospitalares relativamente estruturada e com boa incorporação tecnológica. O município encontrava-se em Gestão Plena do Sistema de Saúde, atendendo a toda região do entorno, composta por 11 municípios.

Na seleção dos sujeitos de estudo decidiu-se por contemplar tanto médicos com maior tempo de carreira profissional e inserção no PSF do município, como outros mais novos, cuja inserção no programa deu-se mais recentemente. Foram selecionados dois profissionais que iniciaram com as primeiras equipes implantadas (1996) e três que fizeram parte do processo de ampliação da cobertura do PSF no município no ano de 1999. Foram realizadas cinco entrevistas em profundidade, gerando um banco de dados com seiscentos minutos de gravação entre trabalho de campo e entrevistas. À medida que este conteúdo era lido e relido no processo de análise, configurava-se a situação de impregnação3 (Schraiber, 1995a). Nos relatos,
${ }^{3}$ Queiroz apud

Schraiber (1995a)

utiliza o termo

exaustão ou saturação -

onde o pesquisador

verifica a formação de

um todo e reconhece a reconstituição do

objeto de pesquisa no

conjunto do material. 
os informantes manifestaram a realidade como fundo de cena, um abrir o mundo, não na sua totalidade, mas como fragmento relevante de uma dada situação (Prado, 1996).

O roteiro das entrevistas, bem como a análise de seu conteúdo estruturou-se com base nas seguintes dimensões: simbólicas: o prestígio, a aceitação pela população e pela corporação; o poder do saber técnico; técnicas: racionalidade e tecnologia; relacionais: as relações do médico com a equipe, com as famílias (e comunidade), dentro e fora da unidade de saúde.

\section{Resultados e discussão}

\section{Apresentando os sujeitos}

Como ponto de partida apresenta-se a seguir um breve perfil dos cinco médicos ${ }^{4}$ inseridos no estudo.

Alice - 53 anos, os pais eram administradores públicos, uma família de classe média ${ }^{5}$. È divorciada e tem dois filhos. Formada há trinta anos, tem residência em pediatria, uma história de prática liberal inicialmente e depois como empresária da medicina. Inseriu-se no PSF após crise familiar. Deslocase diariamente da capital para o município onde atua, e daí para a área rural onde se encontra sua equipe do PSF. Trabalha há quatro anos no mesmo território.

Wilson - 41 anos, pais pequenos comerciantes, uma família de classe média baixa. É solteiro e toma conta da mãe, irmã e do sobrinho. Formado há 14 anos, é médico da Secretaria de Estado da Saúde, plantonista em pequenos hospitais do interior e está inserido no PSF há quatro anos, atuando no mesmo local. Reside na área onde atua.

Walter - 31 anos, casado, dois filhos, família de militares, de classe média alta. Formado há quatro anos, queria fazer residência em cirurgia, mas optou pelo PSF, por questões salariais. Trabalha no programa desde que se formou, na mesma cidade onde mora.

João - 38 anos, solteiro, família de pequenos proprietários rurais. Cuida da mãe viúva, da irmã menor e de seu filho. Fez Serviço Social, depois vestibular para Enfermagem e, por fim, Medicina. Está formado há três anos $e$ desde então atua no PSF. Antes de se formar foi servidor público. Trabalha há dois anos e seis meses neste município, onde reside e teve uma experiência no PSF por seis meses em outro local.

Augusto - 26 anos, família de classe média baixa, de pequenos negociantes. Está formado há dois anos, passou na residência para especialização em Nefrologia, em Brasília, mas optou por ficar com a família no município onde residia e seguir no PSF. Trabalha no programa há dois anos, na mesma equipe e área.

Os médicos que investigamos não são egressos de cursos de pósgraduação em Saúde Coletiva ou, especificamente, Atenção Básica/Saúde da Família. São pediatras, generalistas e recém-formados. Apenas Alice tem residência médica em Pediatria. Este dado corrobora os achados de Machado (2000), que indicam que a maioria dos médicos que atua no PSF do Nordeste é formada em escolas públicas, com baixa qualificação especializada, segundo o critério residência médica.

\author{
${ }^{4}$ Ressalta-se que foram \\ utilizados pseudônimos \\ no artigo para \\ preservar a identidade \\ dos profissionais.
${ }^{5}$ Os conteúdos referentes ao reproduzem posições expressas pelos sido alvo de questionamento os critérios que os guiaram nesta definição. \\ pertencimento de classe \\ informantes, não tendo
}


O perfil destes profissionais corresponde plenamente aos dados encontrados pelo estudo nacional (Machado, 2000) sobre as equipes do PSF, destacando dois aspectos em particular: 1) a residência e especialidades mais comuns dos médicos do PSF são as consideradas básicas: medicina interna, geral comunitária, pediatria e gineco-obstetrícia.; 2) com relação ao tempo de experiência profissional destacam-se dois grupos com situações radicalmente opostas: recém formados que ainda não têm carreiras consolidadas e para os quais o PSF se apresenta como uma alternativa de "mercado de trabalho" $e$ profissionais com larga trajetória profissional, incluindo aqui aposentados ou prestes a recorrer à aposentadoria.

\section{Entre escolher ser e tornar-se um doutor}

Entre os determinantes para a escolha da profissão, referidos pelos sujeitos, destacam-se inicialmente elementos que se revelam menos específicos: influência familiar, seja pela convivência com parentes que exercem a profissão ou pela pressão que a família exerce em torno desta escolha; identificação positiva com profissionais da área; perspectivas favoráveis de inserção profissional futura. Entretanto, na escolha pela medicina, pode-se reconhecer o peso significativo de outros aspectos menos generalizáveis: o prestígio ou status social agregado à profissão que se alia à expectativa de garantir um padrão de renda elevado no futuro, aspirações de caráter humanístico ou ainda a fascinação pelo objeto da medicina e tecnologias utilizadas neste campo.

Escolher ser médico foi assim: desde criança eu tinha essa idéia, um professor que era médico abriu um pouco essa perspectiva ... e eu gostei e comecei a me identificar com a profissão, com os conhecimentos. (Augusto)

Medicina dá muito status, quem entra demonstra inteligência, competência, ou tem mais credibilidade perante o grupo e a sociedade. E a minha relação com a escolha da profissão foi muita em cima da questão do saber; por minha mãe ser uma pessoa analfabeta, ela teve um cuidado muito exemplar em fazer a gente estudar. (Wilson)

eu me vi estudando o corpo humano. Vendo aquela beleza e me apaixonando... descobrindo não só a parte grosseira que é a anatomia, mas as células.. que dá origem a tanta coisa ao pensamento ... ao coração. E os aparelhos! Trabalhar com aquela aparelhagem toda. (João)

foi essa tendência com humanas... por doação, para ter o contato... eu acho que para aliviar o sofrimento... não o físico, mais na medicina, mas o sofrimento de modo geral... a gente poderia ajudar, se doar ... eu resolveria tudo... o sofrimento que eu iria apaziguar. (Alice)

Ao resgatar suas experiências relativas ao período de formação, a partir da 
inserção na escola de medicina, os relatos dos profissionais chamam a atenção para a importância atribuída ao espaço acadêmico e ao entorno social na acumulação de um saber técnico-científico constituído de um conhecimento especializado, reconhecido como de grande complexidade, o qual se convertia em capital simbólico.

Um conhecimento que é reconhecido como 'caixa preta', como elemento tático, envolto numa aura de mistério. Sobre a especialização, esta se apresenta como objeto de desejo do estudante de medicina e continuará sendo para o futuro médico: quanto mais especializado o saber, maior o poder de quem o domina. É o saber fragmentado por repartição do conhecimento em ramos parcelares do saber (Schraiber, 1993).

A escola, mais precisamente, a universidade, por onde passaram os cinco médicos ainda não tinha incorporado um modelo pedagógico voltado para a

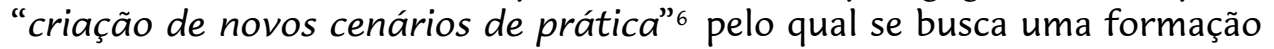
mais próxima da realidade social contrapondo-se a uma visão de um âmbito de prática como "um lugar, em separado, campo e tempo reservado, livre das injunções diretas e imediatas da vida cotidiana" (Marques, 2001, p.143).

Os campos de prática referidos pelos médicos são as maternidades ou casas maternais, os ambulatórios, as emergências e os pronto-socorros públicos, em que a dimensão assistencial-curativa é dominante e é atendida a população mais pobre. Os depoimentos evidenciam que, embora a configuração das atividades práticas não favorecesse aos, então, estudantes de medicina, uma maior aproximação das condições de vida ou do entorno da população atendida, permitia-lhes um contato imediato com as condições reais de organização, infra-estrutura e funcionamento dos serviços públicos de saúde, quase sempre precárias.

Minha formação é de centro cirúrgico, voltado para a área hospitalar; na medida que eu comecei a acompanhar as cirurgias, quando eu passei para o profissional, eu comecei a sentir uma certa dificuldade com a clínica e com a saúde pública. (Walter)

Quando eu comecei a trabalhar com paciente, eu fui estagiar na parte de obstetrícia. E fui assistir um parto, para mim foi uma coisa assim, que eu só não chorei junto com a paciente porque a gente tem que ficar forte, então eu passei uma semana ou mais com aquilo na minha cabeça, martelando. Meu Deus, que estupidez é aquilo, um parto... (João)

Numa maternidade, não tinha leitos suficientes, as mulheres tinham que voltar sem serem atendidas... eu não aceitava, não conseguia entender. (Alice)

O resultado é uma formação centrada no conhecimento biomédico e especializado, na qual se valoriza o médico tecnológico, o especialista "doutor de pedaços". Aprende-se a trabalhar com a técnica, com as máquinas (João), tendo a clínica como sustentáculo da Medicina (Alice).

\author{
${ }^{6}$ O termo cenário de \\ aprendizagem é \\ utilizado segundo um \\ conceito amplo não só \\ se referindo ao local \\ onde se realizam as \\ práticas, como também \\ aos sujeitos nelas \\ envolvidos; a natureza, \\ conteúdo do que se faz. \\ Diz respeito à \\ incorporação e inter- \\ relações entre métodos \\ didáticos pedagógicos, \\ práticas, habilidades, \\ valorização de \\ princípios morais, \\ éticos, orientadores de \\ condutas individuais $e$ \\ coletivas (Feuerwerker, \\ et al., 2000).
}


Em contrapartida, também se aprende sobre a importância da vocação para o exercício da profissão.

Diferentes relatos evidenciam que no processo de formação identitária do médico são valorizados atributos como coragem, frieza e resistência às pressões. Um aprendizado que se nutre de um ambiente coercitivo e 'naturalmente' tenso. Um modelo que pode ser por vezes questionado, mas que termina sendo absorvido sem maiores reações. A aceitação já é uma aliança com a corporação. Tornar-se doutor implica tornar-se membro da "irmandade", do clã e pressupõe a aceitação de normas e modelos em conformidades com seus pares. A identificação com os pares se expressa na linguagem, nos estilos comuns, nas formas de trabalho e até formas de vestir (Moore apud Machado, 2000).

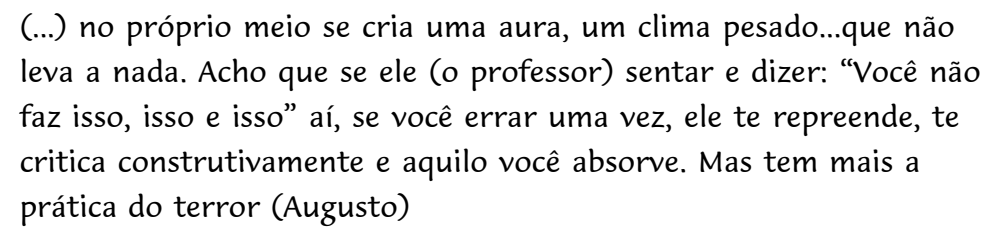

Depois da formatura, surge o dilema de continuar com a especialização nos programas de residência médica ou inserir-se no mercado de trabalho. Isto faz lembrar que a prática médica inscreve-se no bojo de uma ocupação, um meio de subsistência para quem a produz.

Passar nos exames de seleção para a residência é um primeiro desafio. Não conseguindo ter acesso a esses nichos de especialização, resta o mercado de trabalho nos diversos ambientes, nos quais os saberes parcelares são exercidos.

$\mathrm{O}$ mercado $e$ as condições de trabalho são as mais diversas, de hospitais top de linha a ambulatórios ou hospitais com baixa incorporação tecnológica: "plantões, muito trabalho, poucas folgas, onde a gente é explorada, não sabe se recebe em dia ou não" (Alice e João). De fato, a grande maioria dos médicos do Brasil trabalha em mais de três atividades, em regime de plantão $e$ referem-se ao futuro da profissão com pessimismo, incerteza e reclamam do grande desgaste pessoal e profissional (Machado, 2000). Com uma única exceção, o vínculo institucional destes médicos revela outra face perversa do projeto neoliberal - a flexibilização e a precarização do trabalho e das relações trabalhistas.

Encontram-se aqui várias modalidades de prestação de serviços, pois os profissionais podem ocupar os espaços de produtor isolado, ou do trabalho cooperativo ou associado ou, ainda, como produtor e empresário. O assalariamento do médico, já apontado por Schraiber (1995b), e MendesGonçalves (1985), se dá dentro desses espaços: os patrões podem ser os organismos públicos, privados ou filantrópicos.

O mesmo profissional pode ocupar várias posições nas diversas modalidades de prestação de serviços. A história de Alice é típica da fase de 1980 a 1990 - já que a profissional ocupou diversos tipos de postos de trabalho com características da prática tensionada referida por Schraiber (1993): trata-se da situação em que a definição da prática médica é dependente do espaço de atuação e a presença de intermediários mediando o acesso a outros produtos (a 
instituição ou seguro que intervêm no tipo e quantidade de exames) contribui para a institucionalização de diferenças e desigualdades (Alice).

As características da prática médica derivam também da ação ou da omissão do Estado no que tange às políticas de saúde (Paim, 2002). Paradoxalmente, quando abordados sobre temas como o papel do Estado na conformação das políticas públicas ou as implicações da reforma do Estado para a saúde, os médicos investigados relataram que consideravam esses temas como burocracia, coisa do político, da administração, obstáculos às boas práticas (Walter, Alice, Wilson e Augusto).

\section{A inserção no PSF}

A inserção no Programa de Saúde da Família aconteceu para quase todos após submissão a um processo seletivo simplificado. O vínculo trabalhista é formalizado por meio de contratos de trabalho temporários ou outras formas precárias de incorporação. Este dado também coincide plenamente com o quadro geral apontado pela pesquisa nacional (Paim, 2002). A instabilidade do vínculo trabalhista $e$, conseqüentemente, a insegurança que isto provoca no profissional, têm sido apontadas como uns dos principais responsáveis pela alta rotatividade dos profissionais que atuam nas equipes do PSF (Trad, 2003).

A média salarial nacional de 2.229 dólares (em 2002) para o médico do PSF encontrada na pesquisa nacional, considerada como baixa remuneração, não parece ser entendida inicialmente como ruim pelos médicos pesquisados. Em contrapartida, a precariedade dos contratos e a não garantia dos direitos trabalhistas figuram entre as queixas mais recorrentes entre os médicos do programa.

Apontado como um elemento importante na implantação do trabalho das equipes, o processo de capacitação das equipes do PSF é um ponto consensual de crítica entre os sujeitos do estudo. As críticas incluem questões como deficiências na organização e duração: um período pequeno... introdutório mesmo, que fica a desejar (Wilson); da oferta das capacitações à ausência de um consenso em torno de conteúdos e modelos pedagógicos: confuso, tumultuado, muita informação de vez... muita lei, coisas que eu não estava acostumado, sem uma aliança entre a teoria e a prática (Walter).

A experiência de formação do médico prévia ao ingresso no PSF, como vimos no tópico anterior, na qual os conhecimentos da "saúde pública" são tocados de forma marginal, não contribuíram para o desenvolvimento de habilidades que são requisitadas no PSF. Deste modo, será necessário aprender a trabalhar sob outra ótica, com os critérios de territorialização, com enfoque epidemiológico, clientela adscrita e com avaliação baseada em resultados.

Vale registrar que nem todos passaram pelo treinamento introdutório, em que os pressupostos do programa são passados: A implantação do programa no município deu-se de forma improvisada; os profissionais foram inseridos nas unidades sem terem muita clareza sobre os objetivos da proposta. Nestas circunstâncias, ao menos na fase inicial, não está claro o que é ser médico do PSF:

A saúde da família é algo que ouvi falar, que me chamaram e eu fui ou porque se tornou um nicho de mercado melhor que estar dando 2, 3 ou 4 plantões ou ambulatórios por aí ou, (Augusto) ... eu já

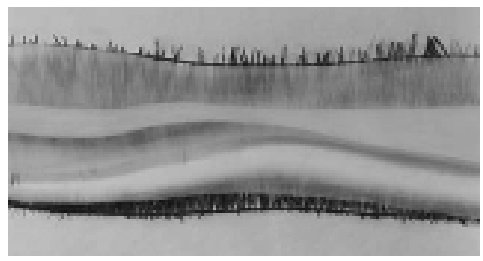


trabalhava em ambulatório e fui para o PSF (Wilson)... Eu queria vivenciar uma área onde a relação com os pacientes fosse outra, onde se tivesse resultado; um outro emprego. (Alice)

A prática típica das unidades básicas tradicionais, baseada exclusivamente em produtividade (leia-se número de consultas) e centrada na consulta médica, deve ceder lugar a uma outra lógica operativa. Os vínculos com os usuários incrementam-se, principalmente os grupos de risco, e são mediados pelo trabalho dos Agentes Comunitários. Deslocando-se por vezes a sítios longínquos, a equipe vai se meter na casa de um camarada (Augusto), que acredita no que o doutor disse (Walter). Na aproximação com os espaços comunitários, com o domicílio, os médicos chegam mais perto das necessidades e carecimentos das pessoas e vão se sensibilizando com suas demandas: "os coitados que vêm pedir socorro, estão precisando e não podem ser ignorados" (Wilson).

A visita domiciliar transforma as relações, estabelece outra dimensão do ato clínico, por trazer à tona um outro tipo de diagnóstico que transmuta o saber contido nos manuais. A concepção que os médicos detêm sobre saúdedoença começa a ser questionada quando se vêem frente a frente com os sintomas da pobreza:

Outro dia eu cheguei na casa de uma paciente, ela fez um parto prematuro uns sete meses (...) Então, eu fui orientar ela em algumas coisas......ai, o que é acontece? O marido diz que lava carro, mal ganha para passar, ela tem três filhos pequenos e mora com mais cinco irmãos do esposo, porque a mãe dele faleceu. Se você visse como era o lugar ...aí entendemos porque ela ficava perguntando se a criança ia ter alta...como iam criar um bebê de risco ali? (Augusto)

É muita gente para cuidar: os do posto, os das casas, os dos grupos: gestantes, hipertensos, diabéticos. Se lhes apresentam metas a cumprir, novas atividades a desempenhar. São as urgências epidemiológicas $e$ sanitárias, que precisam ser prontamente tratadas. Tem as velhas e novas doenças. Aos velhos saberes - a clínica, a obstetrícia etc.- se agregam os novos: planejamento, epidemiologia, educação e comunicação em saúde.

Para acompanhar os grupos de risco, além do conhecimento clínico, é preciso recorrer a outra ciência - a Epidemiologia e privilegiar outra dimensão: a coletiva. As equipes do PSF devem trabalhar com um perfil epidemiológico que se traduz em taxas, indicadores, marcadores e eventos sentinelas. E dão face ao território: a minha área.

A proposta de territorialização pressupõe a organização em rede de unidades de saúde, em um espaço geográfico, que não se limite apenas às características epidemiológicas e demográficas. Pressupõe o diagnóstico e enfrentamento de problemas, a discussão sobre os recursos disponíveis e uma articulação com a administração pública local.

Resolver problemas emerge como algo que o médico começa a cobrar de si mesmo. E não tarda muito para descobrir que a maioria dos problemas 
demanda, para seu enfrentamento, outros tipos de conhecimento, de tecnologias e, sobretudo, de ações que extrapolam a esfera individual de atuação. Em alguns casos, tanto a clínica, quanto a epidemiologia se mostram impotentes para enfrentar os problemas no território e é preciso conviver com os sentimentos de frustração e impotência que emergem diante deste fato.

Teve uma senhora, ela foi abandonada pelo marido(....) Eu percebi que ela tinha se prostituído e comecei a conversar com ela, a fazer um acompanhamento, evitar DSTs e evitar, até, que ela engravidasse (...) era um trabalho que eu estava fazendo com ela, trabalho que custava um sacrifício maior, porque, no outro dia, tinha que pensar nas consultas que não realizei naquela tarde para fazer a visita a ela. Infelizmente não deu resultado....... no final de semana, mataram ela... é um exemplo típico, não é? (Walter)

A assistência à saúde, sob a ótica da saúde da família, exige dos componentes da equipe do PSF uma capacidade de respeitar as diferenças culturais e abrir-se para a troca de experiências com outros profissionais e com a população. Diferentes episódios relatados descrevem situações nas quais os médicos do PSF são testados e questionados de forma profunda no seu saber e no sentido da sua prática, como mostra o exemplo abaixo:

Eu tenho uma paciente, velhinha. Noventa anos, (...) Tinha um monte de gente para atender. Mas ela queria falar, falar (...) sobre a família, a história dela tirando a foto dos filhos, do marido, ai mostrou tudo... e eu ouvindo... Depois que foram saindo ela disse assim "Ah doutor tô aliviada agora. Agora, eu posso não tá boa, mas eu tô bem melhor. O senhor me ouviu e isso foi bom". Quer dizer, às vezes, as pessoas vão lá e vão para serem escutadas, serem ouvidas, ouvidas em seus reclames, então, como médico, eu estou para isso também, para ouvir... E isso acho que vai encurtar uma distância muito grande entre o médico e a população. (Wilson)

As contradições entre uma prática pautada na autoridade absoluta do médico e uma outra que se pretende dialógica, baseada no reconhecimento do caráter plural e multivocal do campo da saúde, revelam-se, por exemplo, nas práticas educativas que, além de fragmentadas, tendem a ser autoritárias e prescritivas.

No dia da reunião com os hipertensos a discussão foi essa: "Você ainda está fumando, eu já vi mesmo que você quer morrer, não vai adiantar a gente lhe tratar e você continuar fumando. Olhe, eu acho bom você ser mais honesto, ouviu? Não leve o remédio que você não vai adiantar de nada!!!". (Alice)

O depoimento acima descreve uma situação na qual o paciente é claramente culpabilizado pelo seu problema. Kleinman (1978) critica a tendência, especialmente no mundo ocidental, de se atribuir à negligência dos indivíduos a origem de muitos problemas de saúde e considera que os programas 
educativos de saúde incorporam esta visão.

No que se refere à dinâmica relacional no interior da equipe, constata-se uma situação na qual os profissionais do PSF estão permanentemente se conhecendo, se estranhando, definindo regras de convivência. Neste contexto, o médico vai aprendendo a negociar e descobrindo que é preciso construir consensos na busca para as soluções dos problemas, o que relativiza o sentido de autonomia profissional. Por outro lado, ele não parece disposto a abrir mão de sua hegemonia dentro da equipe. Neste sentido, a percepção dos entrevistados sobre os demais profissionais alia sentimentos amistosos com reservas dirigidas ao terreno da atuação.

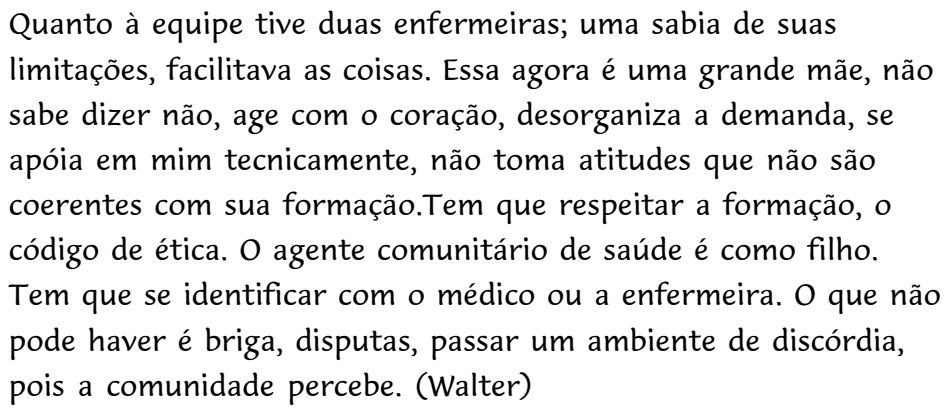

Um ponto de conflito importante, na perspectiva dos médicos, refere-se ao fato de as enfermeiras serem capacitadas ${ }^{7}$ para identificar $e$ atender, em casos de risco, crianças pequenas com diarréia, pneumonia, desidratação, otite e infecções cutâneas. Este fato vem sendo encarado como uma ameaça ao monopólio médico e tem provocado rejeições na categoria médica $e$

${ }^{7}$ O projeto de capacitação utilizado pelo Ministério da Saúde, sob a orientação da Organização Mundial da Saúde - OMS, denominado de Ações Integradas das Doenças Prevalentes na Infância - AIDPI. interferências nos conselhos de classe.

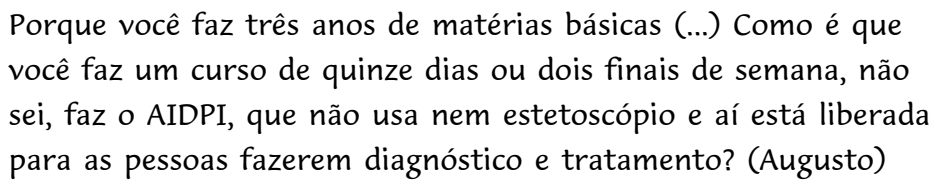

Em contrapartida, a atuação da enfermagem nos programas tradicionais de controle da hanseníase e da tuberculose não foi alvo de questionamentos ou resistência por parte dos médicos. Segundo Mendes-Gonçalves (1990) o monopólio médico se apresenta mais como uma questão política ideológica do que científica.

Os relatos indicam um outro ponto de conflito que, segundo os próprios informantes, tem origem corporativa e está relacionado com o processo de encaminhamento dos pacientes atendidos pelos médicos do PSF para outros serviços de saúde existentes no município - hospitais, centros de referência, ambulatórios de especialidades. De acordo com os entrevistados, os profissionais médicos que atuam no âmbito especializado e hospitalar apresentam uma postura pouco colaboradora e parecem ver no PSF uma ameaça. 
ameaçados, como se estivéssemos acabando com uma reserva de mercado, de mais doentes para eles atenderem (Augusto).

Cabe destacar, por fim, as dificuldades enfrentadas por estes médicos do ponto de vista das condições de trabalho. Além da instabilidade trabalhista, da precariedade dos locais de trabalho (foram recorrentes as queixas quanto a falta de espaço físico adequado, de recursos humanos, de materiais $e$ medicamentos), também foi considerado como desgastante: o excesso de trabalho gerado pelo grande número de famílias atendidas pela equipe, as distâncias a serem percorridas para ir ao campo, a precariedade ou inexistência de veículos para o deslocamento dos profissionais, a manutenção da remuneração no mesmo patamar salarial por quatro anos, atraso no pagamento. A situação se agrava nas áreas rurais, onde as condições das Unidades de Saúde da Família são mais precárias aliadas às dificuldades de comunicação com a sede do município.

Observa-se que os municípios que implantaram o PSF apresentam distintas acumulações político-institucionais, tecnológicas e materiais (Trad et al., 2002), predominando entre eles um quadro de precariedade social e sanitária, como é o caso do município pesquisado. Deste modo, tornar-se um médico do PSF, pode significar, na maioria das vezes, atuar em realidades de saúde negativas, com baixa acumulação tecnológica e estrutural na rede de unidades.

\section{Considerações finais}

As trajetórias profissionais desses cinco médicos, que hoje atuam no PSF, apresentam singularidades recortadas por processos sociais mais amplos, dos quais podemos destacar: a crise da medicina liberal e do modelo hospitalocêntrico; o movimento de experimentação de formas alternativas de organização de serviços e práticas de saúde, influenciadas pelo paradigma da promoção da saúde; tendência a precarização do trabalho.

Tendo como referência as dimensões simbólicas, técnicas e relacionais que nortearam a análise das trajetórias dos médicos, pode-se considerar que a inserção no PSF representa um divisor de águas em suas carreiras. $\mathrm{O}$ conhecimento biológico tecnicista, ancorado nas alterações morfofuncionais, não é suficiente para dar conta de um conjunto de necessidades de saúde da população, que se impõe de modo imperativo no dia a dia de trabalho no âmbito do PSF. Ao tentar assumir a função de autoridade sanitária nas áreas cobertas pelo programa, o médico do PSF é obrigado a agregar novos saberes $e$ práticas, se vê em um cenário em que a hegemonia médica é constantemente questionada. Começa a vivenciar situações no trabalho em saúde nas quais a negociação com atores diversos ganha acento privilegiado.

Neste movimento, o médico passa a questionar os alicerces ideológicos que nortearam historicamente sua prática e se coloca perante a possibilidade de ressignificação da própria identidade profissional. Nos termos de Habermas (1985) é um sujeito "estranhado", que tem diante de si o desafio de superar uma prática mediada pelo agir instrumental, que sempre imperou nas ações de saúde, buscando construir um agir voltado para a reciprocidade (interação).

Parece ressurgir, neste contexto, a velha figura do médico de família que resgata valores comprometidos com a ética humanística. Embora a proposta do 
programa seja distinta em vários aspectos do movimento da Medicina Familiar, conserva deste, como ressalta Paim (1985), elementos como humanização dos cuidados e vínculo entre o serviço e o usuário. As diferenças entre aquele e este médico de família se expressam na esfera de poder. No âmbito do PSF enfatizase o trabalho em equipe e o princípio da co-responsabilidade sanitária, havendo, portanto, uma tendência à diluição do poder corporativo. Embora, na prática, como os dados indicaram, continua conflitante a divisão de trabalho e o poder na equipe.

Cabe registrar, por fim, que este processo é marcado por muitas incertezas. As aspirações ou projetos individuais dos sujeitos são definidos e redefinidos em função das oportunidades $e$ da avaliação das condições concretas que se thes apresentam. A adesão ao PSF pode ser facilitada quando os médicos são seduzidos pelos seus princípios e estes vêm de encontro ao desejo de ruptura com a racionalidade médica tradicional. Entretanto, a experiência prática do programa revela fragilidades de diferentes ordens - infra-estrutura, condições de trabalho, perfil sócio sanitário das áreas atendidas, entre outras - que repercutem claramente na motivação dos profissionais e, certamente, limitam o alcance dos objetivos pretendidos pelo PSF. Cabe destacar que, ao referir-se às condições adversas e aos desafios a serem enfrentados no âmbito de atuação do programa, o médico reclama também para si um tratamento mais humanizado.

\section{Referências}

DONNANGELO, M. C. F. Saúde e sociedade. São Paulo: Livraria Duas Cidades, 1979.

FEUERWERKER. L.; COSTA. H.; RANGEL. L. Diversificação de cenários de ensino e trabalho sobre necessidades/problemas da comunidade. Divulg. Saúde Debate, n.22, p.36-48, 2000.

GRANDA, E.; ARTUNDUA, L. A.; CASTILLO, H.; AMIRA, H.; MERINO, M. C.; TAMAYA, C. El sujeito y la acción en la Salud Publica. Educ. Med. Salud, v.29, n.1, p.1-19, 1995.

HABERMAS, J. Pensamento pos-metafísico: estudos filosóficos. Rio de Janeiro: Tempo Brasileiro, 1990.

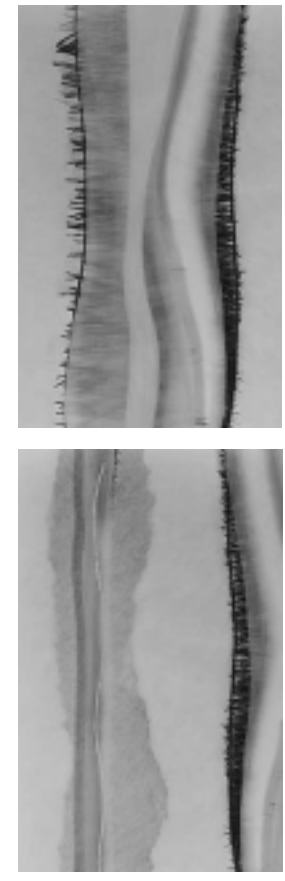

HABERMAS, J. Teoria de la acción comunicativa. versión castellana. Madrid: Taurus, 1985. Tomo 1.

KLEINMAN, A. Concepts and a model for the comparison of medical systems as cultural systems. Social, Scienc. Med., v.12, p.85-93, 1978.

MACHADO, M. H. (Org.) Perfil dos médicos e enfermeiros do Programa Saúde da Família. Brasília: MS/FIOCRUZ, 2000.

MARQUES, M. O. Escola, aprendizagem e docência: imaginário social e intencionalidade política. In: VEIGA, I.P. (Org) Projeto político pedagógico da escola: uma construção possível. 13.ed. São Paulo: Papirus, 2001. p.143-56.

MENDES GONÇALVES, R.B. Medicina e história: raízes sociais do trabalho médico. 1979. Dissertação (Mestrado) - Faculdade de Medicina, Universidade de São Paulo, São Paulo.

MENDES GONÇALVES, R.B. Reflexão sobre a articulação entre a investigação epidemiológica e a prática médica a propósito das doenças crônicas degenerativas. Rio de Janeiro: PEC/ENSP/ABRASCO, 1985.

(Textos de Apoio Epidemiológico I)

MENDES GONÇALVES, R.B. Tecnologia e organização social das práticas de saúde. São Paulo: 
MENESES E ROCHA, A. A. R.; TRAD, L. A. B.

HUCITEC, 1990.

PAIM, J. Saúde política e reforma sanitária. Salvador: ISC, 2002.

PAIM, J.S. Medicina familiar no Brasil: movimento ideológico e ação política. Ensaio. Rev. Bras. Educ. Méd., v.9, n.3, p.207-15, 1985.

PRADO, J.L.A. Brecha na comunicação: Habermas, o outro e Lacan. São Paulo: Hacker, 1996.

SCHRAIBER, L. B. Pesquisa qualitativa em saúde - reflexões metodológicas do relato oral e produção de narrativas em estudo sobre a profissão médica. Rev. Saúde Pública, v. 29, n.1, p 63-73, 1995a.

SCHRAIBER, L. B. O trabalho médico: questões acerca da autonomia profissional. Cad. Saúde

Pública, v.11, n.1, p.57-64, 1995b.

SCHRAIBER, L. B. O médico e seu trabalho: limites da liberdade. São Paulo: HUCITEC, 1993.

TRAD, L. A. B. Programa Saúde da Família: cenários diversos em condições adversas. In: CONGRESSO BRASILEIRO DE SAÚDE COLETIVA, 7., 2003, Brasília. Ciênc. Saúde Coletiva, v.8, p.65, 2003.

TRAD, L. A. B.; BASTOS, A.C. S.; SANTANA, E.M.; NUNES, M. O. Estudo etnográfico de satisfação de usuário do Programa de Saúde da Família (PSF) na Bahia. Ciênc. Saúde Coletiva, v.7, n.3, p.581-9, 2002.

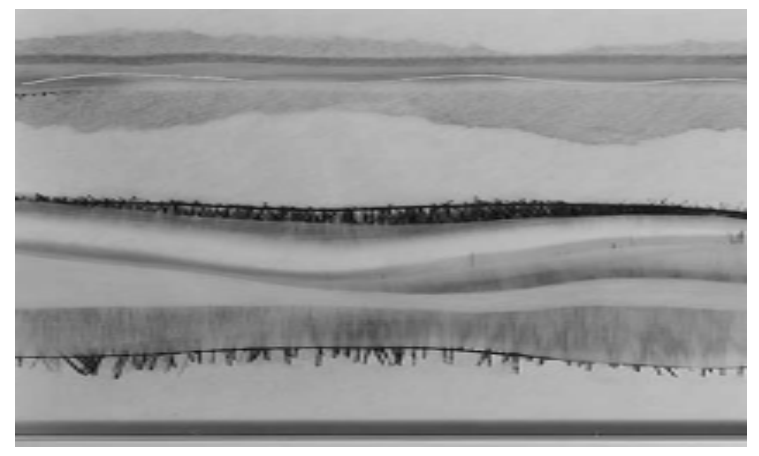

MENESES E ROCHA, A. A. R.; TRAD, L. A. B. La trayectoria profesional de cinco médicos del Programa Salud de la Familia: los desafíos de construcción de una nueva práctica. Interface - Comunic., Saúde, Educ., v.9, n.17, p.303-16, mar/ago 2005.

Este estudio analiza la trayectoria profesional de cinco médicos integrantes del Programa de Salud de la Familia (PSF) en un-municipio del Nordeste de Brasil. A través de historias de vida, circunscritas al ámbito profesional, el estudio enfoca los siguientes factores en la construcción de sus trayectorias: la elección de la profesión, el proceso de formación profesional, la inserción en el mercado de trabajo, particularmente, en el ámbito del PSF. Los datos muestran que el PSF se presenta como un nuevo mercado de trabajo para el médico. El análisis de su práctica en este contexto revela, sin embargo, una tensión entre un conocimiento clínico, que opera en la racionalidad biomédica y es legitimado socialmente, $y$ las acciones de carácter preventivo-promocional priorizadas por el programa. Al mismo tiempo, el PSF parece ser un locus potencial para operar transformaciones en el profesional médico que, como sujeto, puede resignificar su práctica, rescatando las dimensiones humanas $y$ sociales.

PALABRAS CLAVE: médico; trayectoria; salud de la familia; práctica de salud. 